\title{
CHARACTERIZATION OF SPRING AIR POLLUTION OF BEIJING IN 2019 USING ACTIVE AND PASSIVE REMOTE SENSING INSTRUMENTS
}

\author{
Xiaomin Tian ${ }^{1,2}$, Dong Liu ${ }^{1,2,}{ }^{*}$, Songlin $\mathrm{Fu}^{1,2}$, Decheng Wu ${ }^{1}$, Bangxin Wang ${ }^{1}$, Zhenzhu Wang ${ }^{1}$, and Yingjian Wang ${ }^{1,2}$ \\ ${ }^{1}$ Key Laboratory of Atmospheric Optics, Anhui institute of Optics and Fine Mechanics, Chinese Academy of Sciences, Hefei \\ 230031, Anhui, China; - (dchwu, bxwang, zzwang, wyj)@aiofm.ac.cn \\ ${ }^{2}$ University of Science and Technology of China, Hefei 230026, Anhui, China; - (txm, aquarius)@ mail.ustc.edu.cn
}

\section{Commission III, WG III/8}

KEY WORDS: Lidar, Air Pollution, Regional Transport, VIIRS, Haze, Pollution Monitoring

\begin{abstract}
:
As the capital of China, the Beijing area needs to be paid special attention to its air quality. We used active remote sensing instrument (ground-based lidar), combined with passive remote sensing instrument (VIIRS onboard the NPP spacecraft), to study the serious pollution event over Beijing in spring of 2019. At the same time, the ground-based particulate matter (PM) data and the meteorological element data were analyzed. It is found that the ratio of concentrations of PM2.5 to PM10 is very large during the pollution period. The mean value of ratio is 0.75464 , indicated it is fine particulate matter pollution. The Range correction signal (RCS) of lidar is very large in the layer below $0.5 \mathrm{~km}$. But the volume depolarization ratio (VDR) is much less than 0.05 . It indicated it is anthropogenic urban aerosols. The change in the aerosol optical depth (AOD) of VIIRS during pollution is consistent with the change in optical properties observed by lidar. The backward trajectory model of HYSPLIT shows that the pollutant came from the Hebei area where industrial pollution is serious, and the local meteorological conditions in Beijing are conducive to the continuous accumulation of pollutants. This work can deepen the understanding of the mechanism of haze formation and can help and support pollution prevention work.
\end{abstract}

\section{INTRODUCTION}

Beijing is the capital of China and the center of politics, economy, society and culture. Beijing's terrain is high in the northwest and low in the southeast. The west is the Taihang Mountains of Xishan; the north and northeast are the Junshan Mountains of Jundu Mountain. This terrain is likely to cause accumulation of pollutants. What's more, there are many sources of pollution in the surrounding cities. Serious pollution occur in Beijing frequently (Sun et al., 2006). The pollution in Beijing not only affect residents' quality of life (Tian et al., 2019) and social and economic development (Rohde and Muller, 2015), but also affect their international image.

Zhang et al. (2015) analyzed the effects of meteorological anomalies using WRF-Chem. They found that thicker temperature inversion, lower boundary layer and longer duration of southerly winds four recent winter haze episodes in 2010-2014. Zheng et al. (2015) studied the severe winter haze in Beijing during the winter of 2012-2013. They found the severe winter haze was driven by stable synoptic meteorological conditions, and not by an abrupt increase in anthropogenic emissions. Many works have been done like that about cause of the pollution. Change of chemical compositions (Shao et al., 2018; Zhang et al., 2012) during the haze is also caused many concern. Tao et al. (2014) studied on formation process of urban pollution based on satellite and surface observations. Lidar has high spatial and temporal resolution capability and plays an increasingly important role in the detection of haze pollution (Han et al., 2015; Liu et al., 2018; Xie et al., 2008).
This article studied at a continuous haze event that occurred in Beijing from 28 February to 5 March in spring of 2019. The pollution are analysed with active remote sensing instrument (ground-based lidar), passive remote sensing instrument (VIIRS), he ground-based particulate matter, meteorological element and so on.

\section{INSTRUMENTS AND METHODOLOGY}

\subsection{Beijing Meteorological Observatory and Lidar}

Beijing Meteorological Observatory (station No. 54511, $116.47^{\circ} \mathrm{E}, 39.8^{\circ} \mathrm{N}, 31.3 \mathrm{~m}$ above sea level), is located in the southern suburbs. Beijing Observatory, the only station in the entire Beijing meteorological observatory, participate in the exchange of conventional meteorological data all over the world, so the observation data here represent meteorological data in Beijing. In order to analyze the vertical temperature distribution of the atmosphere, the sounding data of the radiosonde at this meteorological observatory was studied.

Lidar system is placed here. The lidar system is a Miepolarized-Raman system with an emission wavelength of 532 $\mathrm{nm}$. Time resolution is 5 minutes. 288 profiles can be detected every day. The spatial resolution of lidar is $0.0075 \mathrm{~m}$ and the detection height is $45 \mathrm{~km}$. Other important parameters are shown in Table 1.

The lidar equation is as follows:

$P(z)=C P_{0} z^{-2}\left[\beta_{\mathrm{m}}(z)+\beta_{a}(z)\right] \exp \left\{-2 \int_{\mathrm{z}_{0}}^{\mathrm{z}}\left[\alpha_{\mathrm{m}}\left(z^{\prime}\right)+\alpha_{a}\left(z^{\prime}\right)\right] \mathrm{d} z^{\prime}\right\}$

\footnotetext{
* Corresponding author
}

dliu@aiofm.cas.cn 
where

$$
\begin{aligned}
& P(z), P_{0}(z)=\text { echo signal power, emission power } \\
& P_{0}(z)=\text { echo signal power } \\
& \mathrm{C}=\text { lidar system constant } \\
& \beta_{m}(z), \beta_{\alpha}(z)=\text { backscattering coefficient of } \\
& \text { molecules and aerosols } \\
& \alpha_{m}(z), \alpha_{a}(z)=\text { extinction coefficient of } \\
& \text { atmospheric molecular and aerosol respectively } \\
& \mathrm{z}_{0}=\text { the height of the lidar }
\end{aligned}
$$

Lidar rang correction signal (RCS) (Kovalev et al., 2009), equation 1 is multiplied by the square of range $\mathrm{z}$, can characterize aerosol content. The bigger the value of RCS, the more content of aerosol. The RCS is represented as TRR in the Figure 1. The volume depolarization ratio (VDR) a is obtained through the ratio of the two channels of polarization signals multiplied by gain ratio. The VDR is commonly used to distinguish between spherical and non-spherical particles. Generally speaking, dust particles are non-spherical particles, and their depolarization ratio is relatively large (>0.2) (Liu et al., 2008a); while aerosol particles of urban pollutant are approximately spherical, and their depolarization ratio is small $(<0.1)$ (Xie et al., 2008).

\begin{tabular}{|l|l|}
\hline Item & \multicolumn{1}{|c|}{ Parameter } \\
\hline Laser & Nd:YAG \\
\hline Wavelength/nm & $532 / 1064$ \\
\hline Pulse energy/mJ & $\geqslant 150 @ 532 \mathrm{~nm}$ \\
\hline Pulse repetition rate/Hz & 10 \\
\hline Beam divergence/mrad & $<0.5$ \\
\hline Telescope & Cassegrain \\
\hline Telescope focal length/m & 2.4 \\
\hline Primary mirror diameter/mm & 300 \\
\hline Range resolution/m & 7.5 \\
\hline
\end{tabular}

Table 1. Main specifications of Lidar

\subsection{Yizhuang Development Zone Air Quality Monitoring Station}

Yizhuang Development Zone Air Quality Monitoring Station is one of 46 monitoring stations of Beijing environmental monitoring center (zx.bjmemc.com.cn/). The concentration data of particulate matter (e.g. PM10, PM2.5) and ambient air pollutants (SO2, NO2, $\mathrm{CO}, \mathrm{O} 3$ ) in Yizhuang monitoring stations are obtained from Beijing Air Quality Release Platform (http://zx.bjmemc.com.cn/getAqiList.shtml?timestamp=155178 6573461).

PM2.5 with diameter less than 2.5 um, called fine particulate matter, is the primary pollutant of environmental pollution now ( $\mathrm{Lu}$ et al., 2015; Wu et al., 2016)). As the latest air quality standard says, air pollution occur with the $24 \mathrm{~h}$-averaged PM2.5 $>75.0 \mathrm{mg}^{*} \mathrm{~m}^{-3}$. When the $24 \mathrm{~h}$-averaged PM2.5 is in the range of $115.0 \mathrm{mg}^{*} \mathrm{~m}^{-3}$ to $250 \mathrm{mg}^{*} \mathrm{~m}^{-3}$, the pollution is moderate level. When the $24 \mathrm{~h}$-average PM2.5 is more than 250 $\mathrm{mg}^{*} \mathrm{~m}^{-3}$, the pollution becomes heavy level (Liu et al., 2018). PM10 with diameter less than $10 \mathrm{um}$, is used to characterize coarse particles, like dust (Han et al., 2015), smoke plume (Yang et al., 2010). Ambient air gaseous pollutant, like SO2, $\mathrm{NO} 2, \mathrm{CO}$ and $\mathrm{O} 3$, will produce sulfates and nitrates after a series of complex atmospheric chemical reactions. As secondary pollutant and the main components of PM2.5, sulfates and nitrates have a great influence on human respiratory tract. What's more, acid rain will form when sulfates and nitrates wets down (Saltman et al., 2005). So changes in the content of gaseous pollutants in ambient air need to be studied. The distance between Yizhuang Station and Beijing Meteorological Observatory is less than $2.9 \mathrm{~km}$. Therefore, the data from these two sites have mutual reference and verification.

\subsection{Passive Remote Sensing Instrument}

VIIRS (Visible Infrared Imaging Radiometer Suite) is a passive remote sensing instruments on-board the National PolarOrbiting Partnership (is short for NPP) spacecraft of America, which was successfully launched on October 28, 2011. It is an extension and improvement instrument of the MODIS, providing the parameters of aerosol, clouds, fire, polar wind snow and ice, sea surface temperature, ocean color, vegetation, and so on (https://ladsweb.modaps.eosdis.nasa.gov/missionsand-measurements/viirs/).

\subsection{HYSPLIT Model}

HYSPLIT (Hybrid Single Particle Lagrangian Integrated Trajectory Model) model is a professional trajectory model establish by the NOAA and the Australian Meteorological Agency for the calculation and analysis of atmospheric pollutant transport and diffusion trajectories (http://ready.arl.noaa.gov/HYSPLIT_traj.php). This model is used for analysing the sources of pollutants.

\section{RESULTS AND DISCUSSIONS}

\subsection{Haze Optics Properties and Time-height Evolution}

Lidar rang correction signal and the volume depolarization ratio are shown in Figure 1. We can know clearly that the VDR (the lower of Figure (a-f)) in the boundary layer is less than 0.1 and large value TRR is concentrated in the near ground layer below $0.5 \mathrm{~km}$ during the whole the pollution period. On 28 February, large values of TRR is distributed below $0.5 \mathrm{~km}$ shows a large amount of aerosol accumulated near the ground layer. During the period from 06:00 to 14:00, the aerosol content is relatively small compared to other time periods. There are some aerosols in the atmosphere ranging from $0.5 \mathrm{~km}$ to $2.0 \mathrm{~km}$ in Figure 1 (a). On 1 March, the aerosol layer shows obvious characteristics of daily variation, with large concentrations in the morning and evening, and low concentration at noon. On 2 March and 3 March, the distribution of aerosols in the near-surface layer was relatively uniform, with no obvious diurnal variation characteristics (see Figure 1 (c) and (d)). During the period from 10:00 to 9:00 on 4 March 2019, the aerosol content near surface layer is relatively less than that of other times, and it also showed daily variation characteristics. On 5 March, there is also a layer of aerosol on the surface layer. After 10:00, its content decrease, indicating that the pollutants begin to dissipate (see in Figure 1 (f)). In general, there is a layer of aerosol near the ground during the entire pollution period. Large concentrations of aerosols accumulate in the near-surface layer below $0.5 \mathrm{~km}$. On February 28th, March 1st and March 4 th, the aerosol near the ground layer showed obvious characteristics of daily variation, with less content at noon and more content in the morning and evening. However, on March 2 and 3, the aerosol distribution was relatively uniform. Since 10:00 on March 5, near-surface aerosol content began to decrease, indicating the dissipation of pollutants. Due to the small VDR value of the pollutant, it can be determined as a spherical urban pollutant. 


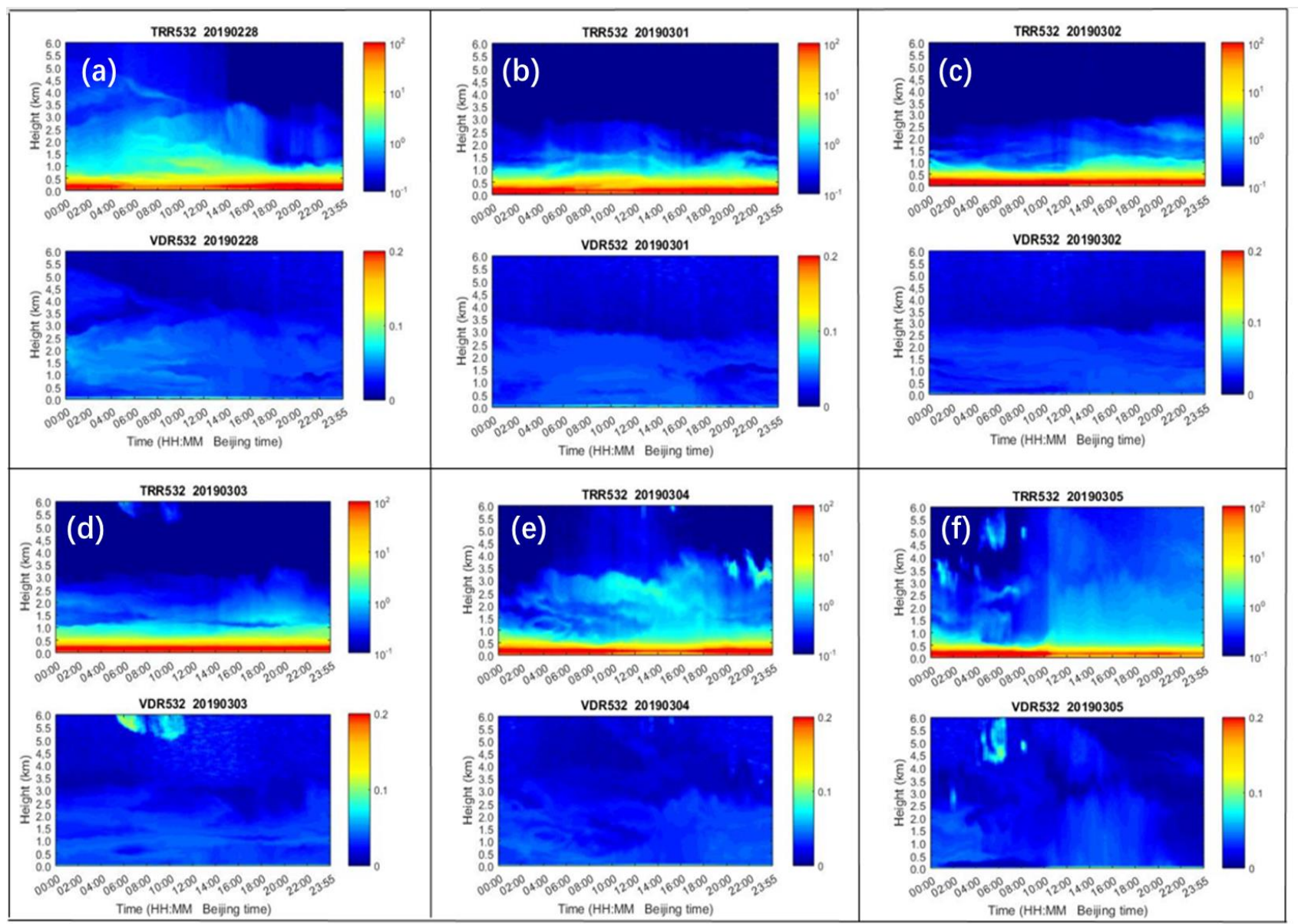

Figure 1. Range correction signal (TRR, the upper) and the volume depolarization ratio (VDR, the lower) from 28 February to 5 March (a-f).
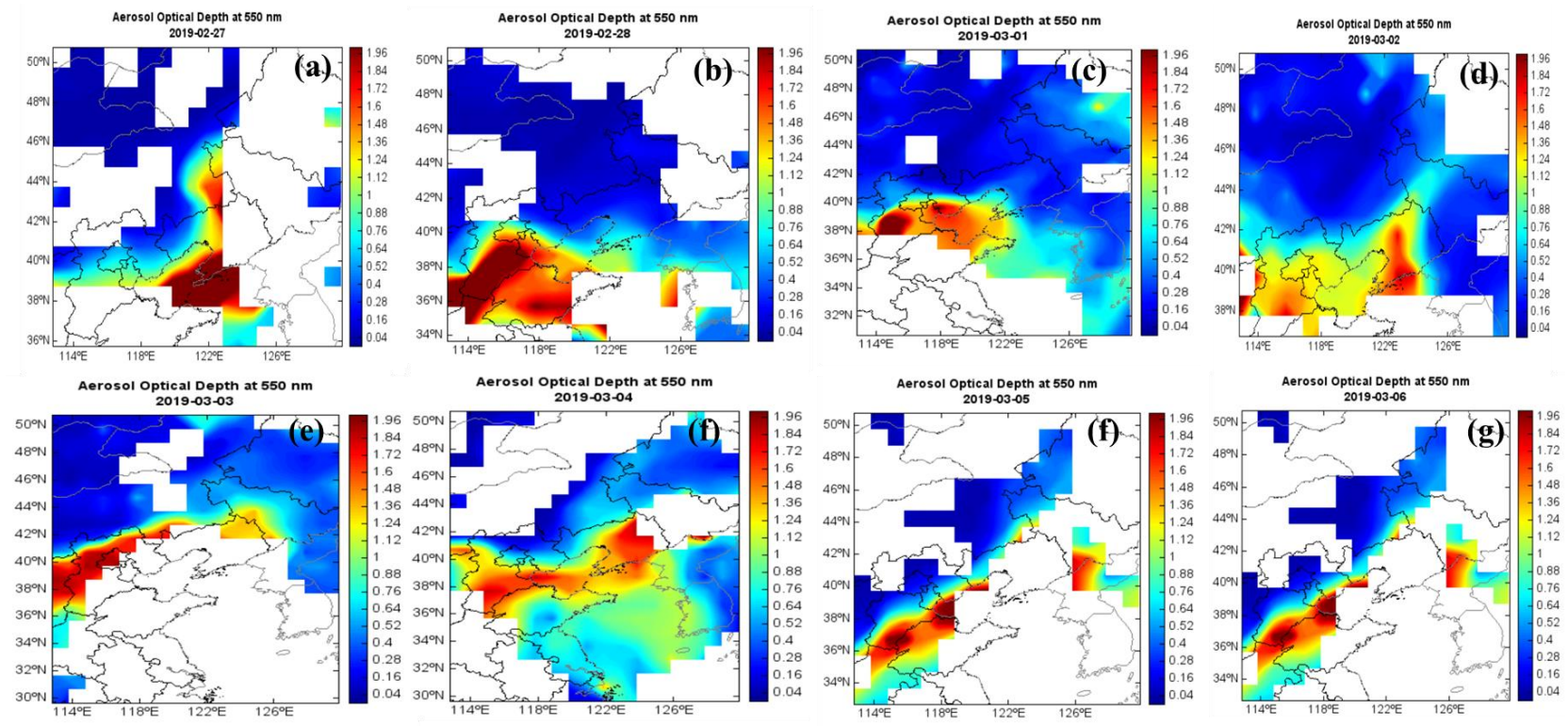

Figure 2. The aerosol optical thickness depth (AOD) of VIIRS from (a-g) 28 February to 6 March.

The pollution process is also completely recorded by VIIRS, AOD from 28 February to 6 March are shown in Figure 2. We can see that AOD of Beijing are larger than 1.6 on 3 March. This day's pollution is the most serious. The AOD on 5 March is less 0.4. Therefore, it indicates that ash pollution is dissipated on the 5th. This result agree with the lidar's result.

\subsection{Change on Air Quality}

This haze event affected seriously the air quality in Beijing. During the whole pollution period from 28 February 2019 to 5 March 2019, the air quality level basically maintains moderate pollution, even reaching severe pollution. The concentration of 
PM2.5 and PM10 are shown in Figure 3 (the upper). It can be found that the concentration of PM2.5 and PM10 is basically maintained above $100 \mathrm{ug} / \mathrm{m}^{3}$, except for the period when pollution begin to appear in 28 February and begin to dissipate in the afternoon of 5 March. What's more, the difference of concentration between PM2.5 and PM10 is very small and the change trend of both are the same. on the 28 February, 1 March and 4 March, the concentration drop significantly at noon. Concentration ratio of PM2.5 to PM10 can be expressed as $\rho(P M 2.5) / \rho(P M 10)$ (the lower of Figure 3). The larger the value of $\rho(P M 2.5) / \rho(P M 10)$, the greater the proportion of PM2.5 in PM10. That is to say, the larger the proportion of fine particles. Analysis found that the mean value is 0.75464 (see in Figure 4). So the pollution is dominated by fine particles.

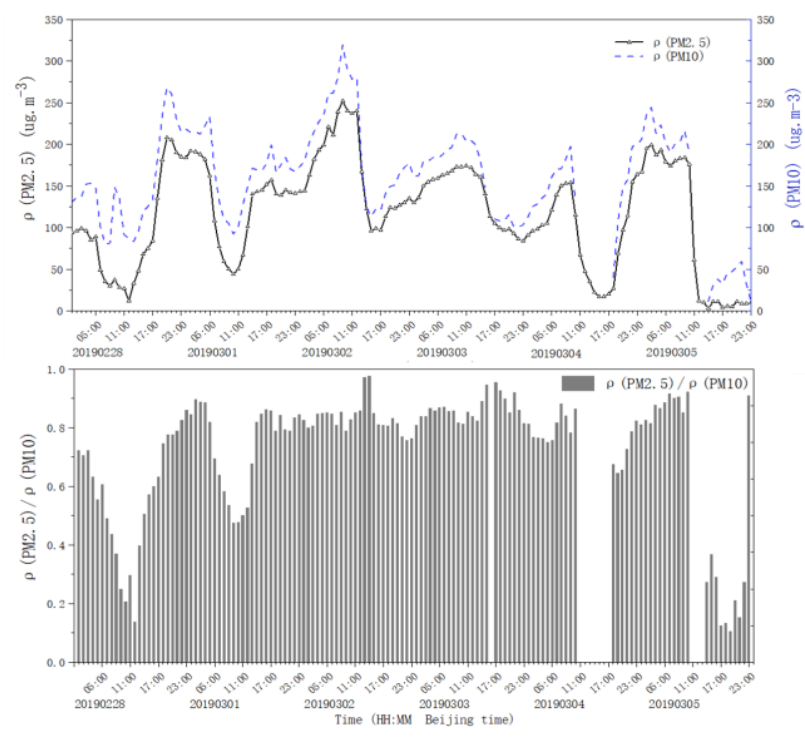

Figure 3. Concentration of PM2.5 and PM10 ( the upper), concentration ratio of PM2.5 to PM10 ( the lower)

Ambient air gaseous pollutant (SO2, NO2, CO and O3) are shown in figure 5 . O3 shows regular diurnal variations. $\mathrm{SO} 2$ is extremely low. The reduction of $\mathrm{SO} 2$ content in the atmosphere may benefit from China's coal desulfurization technology and central heating (Liu et al., 2008b), indicating that the photochemical process of SO2 is weak. The hourly concentrations of $\mathrm{CO}$ were low and varied from 0.8 to $2 \mathrm{ug} / \mathrm{m}^{3}$. the concentration changes of $\mathrm{NO} 2$ are opposite with $\mathrm{O} 3$.

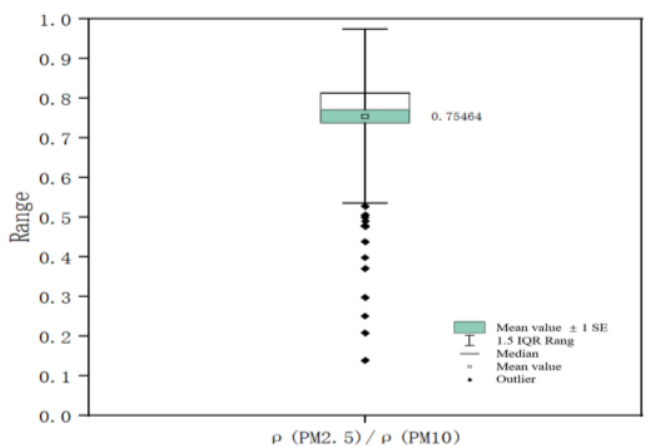

Figure 4. Statistical analysis results of $\rho(P M 2.5) / \rho(P M 10)$

\subsection{Source and Cause of Pollutants}

The concentration of particulate matter (see the Figure 3 ) is less at noon, more in the morning and at night. This is a characteristic of direct pollutants (primary pollutants). Because the boundary layer is relatively low in the morning and evening, and the concentration of pollutants is high. At noon after the sun rises, the boundary layer rises and the pollutants spread upwards, resulting in a relative decrease in pollutant concentration. However, the pollution dominated by secondary pollutants is the opposite. Because of the presence of sun, a series of photochemical reactions will occur to generate secondary particles, resulting in the highest concentration of particles at noon. Therefore, it can be considered that this haze is mainly caused by first pollutant.

It can also be seen from Figure 2 that the AOD in Hebei Province is significantly larger than that in Beijing, indicating that the pollution situation in Hebei is more serious than that in Beijing. We suspect that the source of this aerosol is likely to come from external transport. Therefore, multiple trajectories ensemble of 500m air mass of Beijing are analysed by using the HYSPLIT backward trajectory model. The result is shown in Figure 6 . The results show that the air masses is basically from the Hebei region, which confirms that the pollution is indeed caused external input from Hebei.
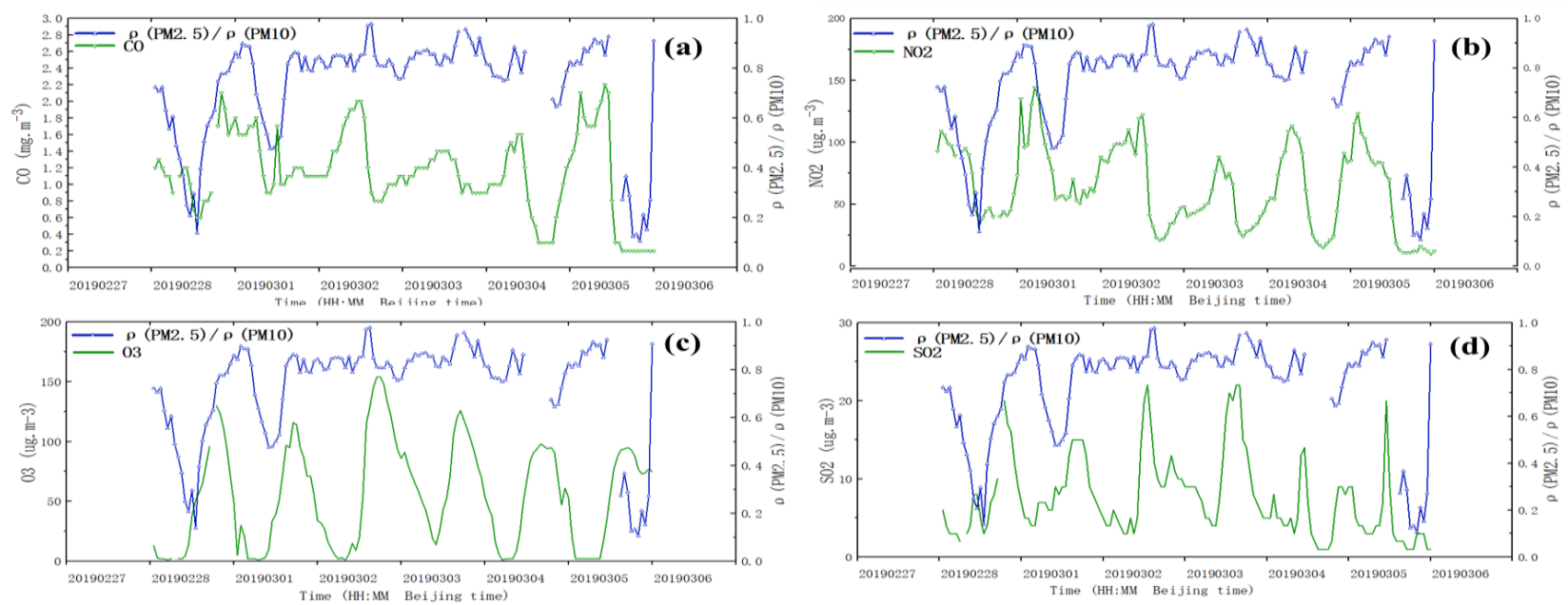

Figure 5. Concentrations of CO (a), NO2 (b), O3 (c) and SO2 (d) in Beijing from 28 January to 5 March 2019 
During the pollution period, the near-surface wind speed is small, basically less than $4 \mathrm{~m} / \mathrm{s}$. And as can be seen from the Figure 7, there is an inversion layer below 500 during almost the entire pollution period. Moreover, on 3 March, another inversion layer appeared at a relatively high altitude. At 08:00, an inversion layer appeared at a height range of $1000 \mathrm{~m}$ to $1500 \mathrm{~m}$. At 20:00, the height of the inversion layer was $800 \mathrm{~m}$ to $1200 \mathrm{~m}$. The small wind speed and the appearance of the inversion layer will inhibit the horizontal and vertical diffusion of pollutants, resulting in accumulation of pollutants. Therefore, this haze formed by the interaction of external pollutants and unfavourable meteorological conditions.

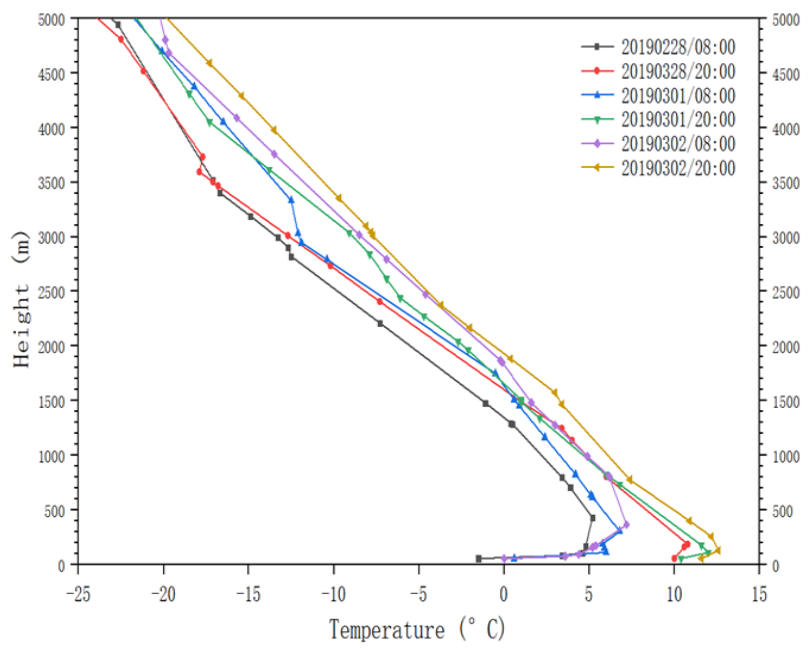

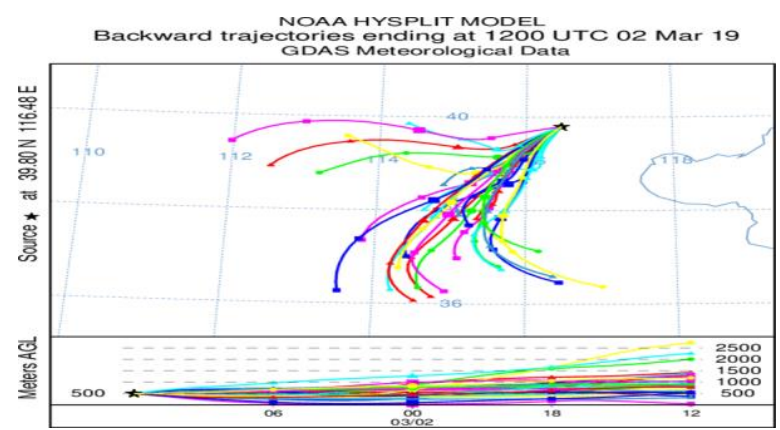

Figure 6. 24-h backward trajectories on 20 March 2019 of Beijing time (=UTC+8)

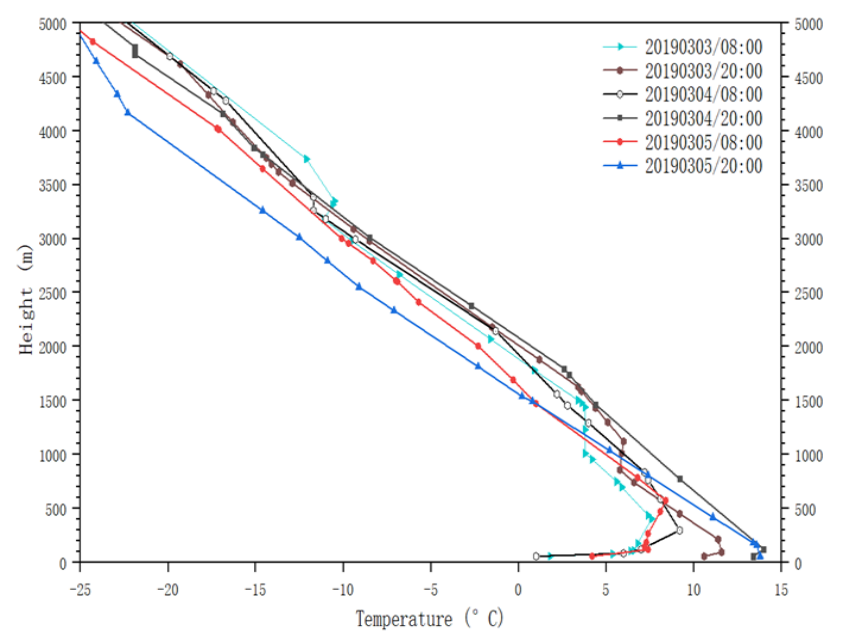

Figure 7. Vertical profiles of temperature in Beijing from 28 January to 5 March 2019

\section{CONCLUSIONS}

A continuous haze pollution occur in the spring of Beijing, from 28 February to 5 March of 2019. The temporal and spatial distribution and optical properties and their causes and sources are analysed, using lidar, VIIRS and HYSPLIT Model together with ambient air gaseous pollutant, particulate matter and meteorological parameters.

The results of the lidar show that the pollutants are basically distributed in surface layer below $0.5 \mathrm{~km}$, and the depolarization ratio indicates that the contaminants are spherical particles. On 28 February, 1March and 4 March, changes of aerosol has regular diurnal variations. Ground-based particles also showed this change. At the same time, the particulate matter indicates that the pollution is mainly fine particle pollution. In general, this haze formed by the interaction of external pollutants and unfavourable meteorological conditions. This work can deepen the understanding of the mechanism of haze formation and can help and support pollution prevention work.

\section{ACKNOWLEDGEMENTS}

This research was funded by the Youth Innovation Promotion Association of Chinese Academy of Sciences under No. 2017482 and by the Science and Technology Service Network Initiative (STS) under No. KFJ-STS-QYZD-022. The authors would like to thank the Beijing municipal environmental monitoring center for particulate matter (PM) data (http://zx.bjmemc.com.cn/).

\section{REFERENCES}

Han, Y., Wu, Y., Wang, T., Xie, C., Zhao, K., Zhuang, B., Li, S., 2015. Characterizing a persistent Asian dust transport event: Optical properties and impact on air quality through the groundbased and satellite measurements over Nanjing, China. Atmospheric Environment, 115, 304-316.

Kovalev, V.A., Cyle, W., Alexander, P., Min, H.W., 2009. Alternative method for determining the constant offset in lidar signal. Applied Optics, 48, 2559-2565.

Liu, B., Ma, Y., Gong, W., Zhang, M., Yang, J., 2018. Study of continuous air pollution in winter over Wuhan based on groundbased and satellite observations. Atmospheric Pollution Research, 9, 156-165.

Liu, D., Wang, Z., Liu, Z., Winker, D., Trepte, C., 2008a. A height resolved global view of dust aerosols from the first year CALIPSO lidar measurements. Journal of Geophysical Research:Atmospheres, 113, D16214.

Liu, Y., Zhou, Y., Peng, J., Zhang, M., 2008b. Experimental study on the enhanced absorption of $\mathrm{SO} 2$ with aqueous hydrogen peroxide solution based on semi-dry flue gas desulfurization. Journal of Fuel Chemistry and Technology, 36, 474-477.

Lu, F., Xu, D., Cheng, Y., Dong, S., Guo, C., Jiang, X., Zheng, X., 2015. Systematic review and meta-analysis of the adverse 
health effects of ambient PM2.5 and PM10 pollution in the Chinese population. Journal Environmental Research, 136, 196-204.

Saltman, T., Cook, R., Fenn, M., Haeuber, R., Mclaughlin, S., 2005. National Acid Precipitation Assessment Program Report to Congress: An Integrated Assessment. Journal Environmental Policy Collection, 305, 346-347.

Shao, P., Tian, H., Sun, Y., Liu, H., Wu, B., Liu, S., Liu, X., Wu, Y., Liang, W., Wang, Y., Gao, J., Xue, Y., Bai, X., Liu, W., Lin, S., Hu, G., 2018. Characterizing remarkable changes of severe haze events and chemical compositions in multi-size airborne particles (PM1, PM2.5 and PM10) from January 2013 to 2016-2017 winter in Beijing, China. Atmospheric Environment, 189, 133-144.

Tao, M., Chen, L., Wang, Z., Ma, P., Tao, J., Jia, S., 2014. A study of urban pollution and haze clouds over northern China during the dusty season based on satellite and surface observations. Atmospheric Environment, 82, 183-192.

Wu, Y., Gu, B., Erisman, J.W., Reis, S., Fang, Y., Lu, X., Zhang, X.J.E.P., 2016. PM2.5 pollution is substantially affected by ammonia emissions in China. Journal Environmental Pollution, 218, 86-94.

Xie, C., Nishizawa, T., Sugimoto, N., Matsui, I., Wang, Z., 2008. Characteristics of aerosol optical properties in pollution and Asian dust episodes over Beijing, China. Applied Optics, 47, 4945-4951.

Yang, H., Liu, M., Liufu, Y., 2010. Research and Simulation of Straw Crop Burning in Anhui and Henan Provinces Using CALPUFF. Research of Environmental Sciences (in Chinese), 23, 1368-1375.

Zhang, L., Wang, T., Lv, M., Zhang, Q., 2015. On the severe haze in Beijing during January 2013: Unraveling the effects of meteorological anomalies with WRF-Chem. Atmospheric Environment, 104, 11-21.

Zhang, X., Zhang, Y., Cao, G., 2012. Aerosol Chemical Compositions of Beijing PM_1 and Its Control Countermeasures. Journal of Applied Meteorological Science, 23, 257-264.

Zheng, G.J., Duan, F.K., Su, H., Ma, Y.L., Cheng, Y., Zheng, B., Zhang, Q., Huang, T., Kimoto, T., Chang, D., 2015. Exploring the severe winter haze in Beijing: The impact of synoptic weather, regional transport and heterogeneous reactions. Atmospheric Chemistry and Physics, 15, 2969-2983. 